\title{
Das cartas à impressão: uma trajetória
}

\author{
Célia Marques Telles \\ (UFBA)
}

\section{Introdução}

Tem-se freqüentemente assinalado que as cartas ${ }^{1}$ de Arthur de Salles ${ }^{2}$ a Durval de Moraes $^{3}$ são ricas de informações sobre os textos definitivos do poeta ${ }^{4}$. A partir

\begin{abstract}
' Por intermédio de D. Celina Salles Trigueiros, fillha do poeta, o Grupo de Edição Crítica de Textos do Setor de Filologia Românica do DFEL/UFBA obteve as cópias xerox com que trabalha, cedidas pelo Dr. Julival de Moraes, filho de Durval de Moraes.

2 Arthur Gonçalves de Salles (1879-1952) é um poeta baiano da fase pré-modernista, classificado pela tradição historiográfica como simbolista e parnasiano. Foi um dos jovens criadores da revista Nova Cruqada e sócio fundador da Academia de Letras da Bahia. Professor Primário formado em 1905 pela Escola Normal, foi Bibliotecário da Escola Agrícola da Bahia e em 1911 passou a Adjunto do Curso Primário do Aprendizado Agrícola da Bahia, cargo que ocupou até 1930. Lecionou em escolas de Salvador e de cidades de Sergipe até 1940, quando se aposentou. Sua obra - poesia e prosa - é extensa, embora tenha publicado apenas três livros e uma tradução do Macbeth de W. Shakespeare, precedida de um "Prefácio". Sua obra dispersa é, portanto, considerável e são inúmeros os seus inéditos.
\end{abstract}

${ }^{3}$ Durval Borges de Moraes (1882-1948) diplomou-se como Químico-Farmacêutico pela Faculdade de Medicina, em 1907. Foi assistente de Química Vegetal na Escola Agrícola da Bahia, de onde saiu para Monte Azul (São Paulo), e depois para o Rio de Janeiro, onde foi Preparador de Química da Escola Politécnica da Universidade do Brasil. Simbolista, foi considerado "O Principe dos poetas baianos", desde a publicação do primeiro livro, A Sombra fecunda (1913). Grande parte de sua obra acha-se publicada em jornais e revistas, mas existem ainda inéditos. Escreveu e publicou também peças teatrais. São publicações póstumas: Plasmas II e Ouro de fôlhas mortas, ambos de 1965. Como dramaturgo, é considerado por Eudynir Fraga como autor da única obra teatral brasileira integralmente comprometida com o movimento simbolista.

4 Cf. Nilton Vasco da GAMA, Célia Marques TELLES. A obra de Arthur de Salles contida na sua correspondência a Durval de Moraes. In: Jacyra MOTA (org.). Congressso Internacional da Associaşão Brasileira de Lingüistica, 1; atas. Salvador: ABRALIN/ UFBA, 1997. v.2, disq. 7, linghist., com. 8; Albertina Ribeiro da G.ANLA, Célia Marques TELLES. Alguns aspectos da cultura baiana nas cartas de Arthur de Salles a Durval de Moraes. Caderno do Centro de Pesquisas Literárias da PUCRS, Porto Alegre, v.2, n.2, p. 92-100, jul. 1996. Anais do 2. Encontro Nacional de Acervos Literários Brasileiros. 
das cartas de Arthur de Salles ao poeta Durval de Moraes que documentam textos definitivos da obra do poeta baiano, buscar-se-á traçar $3 / 4$ no projeto A Obra de Arthur de Salles nas cartas a Durval de Moraes $3 / 4$ a trajetória entre a última versão autoral e a sua primeira publicação. Esses dados serão complementados pelo resultado a que já se chegou na recensio $3 / 4$ ainda que parcial, com o desenvolvimento do projeto Levantamento em periódicos da obra dispersa de Artbur de Salles". A trajetória entre o manuscrito e a primeira impressão da obra do vate baiano vem sendo rastreada sobretudo com o exame dessas cartas a Durval de Moraes.

A importância da correspondência entre os dois poetas foi assinalada mais de uma vez nas entrevistas com seus familiares ou com Hélio Simões. D. Celina Salles Tigueiros, filha do poeta, citou-as pela primeira vez em março de 1979, depois em 27 de julho de 1981, tendo conseguido localizá-las em junho de 1982 . O jornalista Antônio Loureiro de souza, em 14 de maio de 1980, informou que nada encontrara da correspondência de Durval de Moraes a Arthur de Salles ${ }^{7}$; não confirmou, entretanto, o fato de Durval de Moraes ter feito uma conferência em Sào Paulo sobre as cartas de Arthur de Salles, informaçào atribuida a Astério de Campos ${ }^{8}$. O professor Hélio Simòes referia-se sempre ao valor literário da correspondência entre Salles e Moraes.

As 223 cartas que integram o acervo Julival de Moraes - datadas entre 1908 e 1935 - compreendem 221 cartas de Arthur de Salles a Durval de Moraes e duas, em rascunho ainda, deste a Arthur de Salles. Encontram-se classificadas em cinco grupos ${ }^{9}$ de que apenas três interessam para essa análise:

1. Carta + trechos completos. Datadas de 1918-1924, compreendem 11 poemas que integrarão o livro Poesias ${ }^{11}$, dentre eles os pórticos, como os chamou Arthur de Salles. Os demais poemas foram catalogados como Dispersos.

\footnotetext{
Trata-se do primeiro subprojeto que integra o Projeto Integrado Resgates da Memória Cultural: acervos baianos, financiado pelo CNPq a partir de setembro de 1997.

${ }^{6}$ Projeto apresentado para o PIBIC, desde 1995, que se ocupa da construção da recensio da obra impressa de Arthur de Salles

${ }^{7} \mathrm{~A}$ Coleção Arthur de Salles, no Acervo do Setor de Filologia România, integrante do Acervo de Manuscritos Baianos do Instituto de Letras da UFBA, possui apenas dois documentos autógrafo de Durval de Moraes (020:0172 e 043:0214), parte de uma carta a Arthur de Salles.

${ }^{8}$ Cf. Astério de CAMPOS. Um Escriptor bahiano. In: id. Varios escriptos; 1911-1916. Salvador: Imprensa Official do Estado, [s.d.]. p. 89-91.

"Cf. Nilton Vasco da GAMA, Célia Marques TELLES, art. cit.

"Cf. Arthur de SALLES. Poesias; 1901-1915. Salvador: Imprensa Official, 1920. 252+ivp. I1. Com uma sanguinea de Presciliano Silva.
} 
2. Poemas completos, grupo em que estào arrolados os poemas encontrados na correspondência sem qualquer referência à carta que os encaminhava. São ao todo 17 composiçòes, das quais 12 datadas entre 1908 e 1918.

3. Cartas-poema, sete cartas redigidas em versos, seis delas datadas de 19111924.

Nessas cartas encontram-se ao todo 32 poemas ${ }^{11}$, dos quais alguns foram publicados em livro (Poesias ${ }^{12}$ ); a sua maioria, porém, teve publicação em periódicos. As cartas-poema nào se acham publicadas. Por outro lado, uma carta deu origem a uma crônica, Os Multungus ${ }^{13}$.

\section{Das cartas ao texto impresso}

O texto (poesia ou prosa) enviado ao amigo Durval de Moraes aparece publicado pouco tempo depois em uma revista de circulação nacional. O percurso entre o manuscrito definitivo e a primeira publicaçào do poema, acompanhando o trajeto da obra e a importância de Durval de Moraes na divulgação da mesma, pode ser traçado sem maiores dificuldades. O inverso também é verdadeiro, pois, como já se pôde verificar ${ }^{14}$, Arthur de Salles publicava em revistas da Bahia trabalhos que lhe eram enviados por Durval de Moraes.

\footnotetext{
"Intenta-se, ao final do trabalho, publicar a edição crítica dos poemas, respeitando os cortes já feitos no material que será incluído em teses de doutorado ou dissertações de mestrado. Rosa Borges Santos Carvalho, apresentou como projeto para o Curso de Doutorado em Letras uma proposta de edição crítica dos Poemas do Mar de Arthur de Salles, dando, assim, continuidade ao seu trabalho da dissertação apresentada ao Curso de Mestrado em Letras. Cf. Rosa Borges Santos CARVALHO. "Poemas do mar" de Arthur de Salles: tentativa de edição crítica. Salvador: UFBA/PPGLL, 1995. Dissertação apresentada ao Curso de Mestrado em Letras, orient. por Nilton Vasco da Gama. Maria Dolores Teles, trabalhando com a obra dispersa, e Eliana Correia Brandão, trabalhando com os éditos publicados em Poesias, ocupam-se da edição em suas dissertaçõers de Mestrado.

${ }^{12}$ Cf. ed. cit.

${ }^{13}$ T'exto em prosa que será editado por Maria Dolores Teles. Cf., a propósito de Os Mulungus, os trabalhos de Célia Goulart de Freitas TAVARES. Alguns aspeitos da prosa dispersa e inédita de Arthur de Salles. Salvador: UFBA, 1986. Dissertação apresentada ao Curso de Mestrado em Letras, orient. Por Nilton Vasco da Gama; id. Considerações sobre a prosa dispersa e inédita de Arthur de Salles. Comunicação apresentada nos Seminários de Filologia Românica, Salvador, UFBA, 29.08.95.

${ }^{14}$ Cf. Célia Marques TELLES. Uma carta de Durval de Moraes a Arthur de Salles. Qvinto Império, Salvador, n. 6, p. 87-103, 1996.
} 
O primeiro grupo de cartas, carta + trechos completos, engloba os poemas

Canção de amor ${ }^{15}$,

Rosas de Antanbo ${ }^{16}$,

Purpuras ${ }^{17}$,

Ermo em flôr ${ }^{18}$,

Vida Pagan $I^{19}$,

$I I^{20}, I I I^{11}$,

Hymno à Alegria ${ }^{22}$,

Elogio da Solidão ${ }^{23}$,

Veneza ${ }^{2+}$,

Sub umbra $a^{25}$.

Por sua vez, o segundo grupo, Poemas completos, compreende as composiçōes poéticas:

\author{
Dupla revolta $a^{26}$, \\ O cão de bordon ${ }^{27}$, \\ Signu. ${ }^{28}$, \\ Per viam vitae ${ }^{29}$, \\ O Cavalleiro das Horas Mortas / \\ Ballada ${ }^{30}$,
}

\footnotetext{
${ }^{15}$ Cf. doc. 065:0299, 09.03.914, 2r ${ }^{\circ}$.-6r'. Citam-se os manuscritos sempre com esses dois números, extraidos da notação do documento: o primeiro refere-se à pasta e o segundo, à identificação do documento.

${ }^{16}$ Cf. doc. 067:0330, 04.01.918, $4 \mathrm{r}^{\prime \prime} .-5 \mathrm{r}^{\circ}$.

${ }^{17}$ Cf. id., 6r ${ }^{\circ}$.

${ }^{18} \mathrm{Cf}$. id., $7 \mathrm{r}^{\circ}$.

${ }^{19}$ Cf. id., $8 \mathrm{r}^{\circ}$.

${ }^{20} \mathrm{Cf}$. id., $9 \mathrm{r}^{\circ}$.

${ }^{21}$ Cf. id. $10 \mathrm{r}$ ".

${ }^{22}$ Cf. doc. 067:0337, 17.03.919, 3r ${ }^{\circ}$.

${ }^{23}$ Cf. id. $4 r^{\circ}$.

${ }^{24}$ Cf. doc. 070:0391, 16.05.924, 2r ${ }^{\circ}$.

${ }^{25} \mathrm{Cf}$. id. $3 \mathrm{r}^{\circ},-4 \mathrm{r}^{\circ}$.

${ }^{26} \mathrm{Cf}$. doc. 061:0233, 16.11.908, $1 \mathrm{r}^{\mathrm{o}}$.

${ }^{27} \mathrm{Cf}$. doc. 063: 0259, 26.03.912, $1 \mathrm{r}^{\circ} .-3 \mathrm{r}^{\mathrm{o}}$.

${ }^{28}$ Cf. doc. 063:0262, 13.06.912, $1 \mathrm{r}^{\circ}$.

${ }^{29)}$ Cf. id., 16.06.912, $2 \mathrm{r}^{\circ} .-3 \mathrm{r}^{\circ}$.

${ }^{31}$ Cf. doc. 063:0263, 07.910, $1 \mathrm{r}^{\circ} .-3 \mathrm{r}^{\circ}$.
} 
A Janella do Oriente, ${ }^{31}$

A Noute, o Mar, os Mortos... ${ }^{32}$,

A Lagôa $a^{33}$,

A Mulher da hora morta ${ }^{34}$,

D. Quixote ${ }^{35}$,

A mercê das scismas ${ }^{36}$,

Pela cidade das Ruinas ${ }^{37}$,

Praia em festa ${ }^{38}$,

Sub umbra ${ }^{39}$,

A uma taça partida ${ }^{40}$.

Ao terceiro grupo pertencem:

Durval: / "Tú na tristera immensa desse exilio" $(. . .)^{+1}$,

Durval: / "Um dia a sombra amarga da tristeza" (... $)^{42}$,

Durval: / "Dizes bem, meu amigo, silencia" $(. . .)^{+3}$,

Durval: / "Meu formoso Monte Aqul” (....),

"Irei por ti atraves a canção" / Durval: / "Já por longos momentos" (... $)^{15}$,

Durval / "7 de Março de 1879" / "Poesia..." (...) $)^{\text {th }}$,

Durval: / "Vae, pela noute föra," $(. . .)^{\text {ti }}$

${ }^{3}$ Cf. doc. 063:0269, 09.08.912, $1 \mathrm{r}$.

"Cf. doc. 064:0287, 24.04.913, 1r".

"Cf. doc. 065:0302, 13.04.914, 1r".

${ }^{34}$ Cf. id. $2 r^{\circ}$.

${ }^{35}$ Cf. doc. 067:0332, 03.918, $1 \mathrm{r}^{\circ}$.

${ }^{36}$ Cf. doc. 072:0429, [s.d.], $1 \mathrm{r}^{\circ} .-5 \mathrm{r}^{\circ}$.

${ }^{37}$ Cf. doc. 072:0430, [s.d.], $1 \mathrm{r}^{\circ} .-4 \mathrm{r}^{\circ}$.

${ }^{38}$ Cf. doc. 072:0431, [s.d.], $1 \mathrm{r}^{\circ} .-3 \mathrm{r}^{\circ}$.

${ }^{39}$ Cf. doc. 072:0432, [s.d.], $1 \mathrm{r}^{\circ} .-2 \mathrm{r}^{\circ}$.

"I" Cf. doc. 072:0435, [s.d.], $1 \mathrm{r}^{\prime \prime} .-2 \mathrm{r}^{\prime \prime}$.

${ }^{4}$ Cf. doc. 062:0244, 23.06.911.

12 Cf. doc. 062:0251, 30.11.911.

${ }^{13}$ Ce. doc. 064:0267, 08.08.912.

${ }^{4}$ Cf. doc. 064:0284, 05.04.913.

${ }^{45}$ Cf. doc. 066:0315, [s.d.].

${ }^{46}$ Cf. doc. 069:0363, 07.03.924.

${ }^{47}$ Cf. doc. 072:0428, [s.d.]. 
A partir do fato de o soneto Ermitão contido em uma das duas cartas de Durval de Moraes a Arthur de Salles, 3/4 decomposto em versos livres, dedicado pelo primeiro ao segundo ${ }^{+9}$ : o manuscrito $073: 440^{50}$, com datação a quo de março de 1914 3/4 aparecer publicado com intermediação de Arthur de Salles na revista Annaes, de Carlos Weber ${ }^{51}$, permite-se admitir a hipótese de poder acompanhar a trajetória dos textos do manuscrito para a imprensa.

Arthur de Salles afirma em cartas a Durval de Moraes:

Em carta separada envio-lhe uns versos de que não guardei cópia: $O$ [sic] correio extraviou ${ }^{52}$.

Dous obsequios a te pedir: a publicação de meus versos [riscado ilegível] $\mathrm{Na}$ hora da prece [sublinhado] porque não os tenho mais. Repara que a Renascença publicou com uma revisão péssima ${ }^{53}$.

... Ahi vão estes versos que encontrei mais a mão, ao remecher [sic] a minha papelada aqui em Brotas. Certamente outros irão as tuas mãos porque preciso de alguma cousa que me distraia desta esmagadora e bruta tristeza que pesa sobre minhalma [sic] pobre alma. Mandar-te-ei o Anchieta e o que for encontrando. Faze delles o que quiseres... ${ }^{5+}$

A partir do texto das cartas pode notar-se a desorganização aparente do poeta, na realidade ele não guardou uma cópia dos versos entregues a outrem. Por

${ }^{48}$ Cf. Célia Marques TELLES. Uma carta de Durval de Moraes a Arthur de Salles...

49 Cf PR-EP-CO-OM-073:0440-XE:01-09/JM. Autógrafo. Rascunho. Tiras de papel escritas no recto, medindo $380,4 \times 150,3 \mathrm{~mm}$. 8 fólios. Sem data. A scripta mostra a existência de três campanhas no texto. Datação a quo: março de 1914

${ }^{50}$ Data em que o soneto foi publicado na revista Annaes (Bahia, ano IV, n. 3, março de 1914). A catalogação dessa versão publicada do soneto é resultado da pesquisa desenvolvida pela bolsista Lilane Coutinho Duques, dentro do Projeto Levantamento em Periódicos da Obra dispersa de Arthur de Salles.

${ }^{5}$ Deve ser a essa publicação que Arthur de Salles refere-se em carta: "O Weber vae este mez publicar os "Annaes"- Li uns versos teus e tenho aqui para concertar a "Na hora da prece" (cf. doc. 064:0285, 12.04.1913, $\left.\mathrm{f}^{\circ} 1\right)$.

${ }^{52}$ Cf. doc. 071:0401, data ad quem 24.11.1911.

${ }^{53}$ Cf. doc. 071:0409, anterior a 10.02.?.

${ }^{54}$ Cf. doc. 070: 0391, 16 de maio de 1924. 
outro lado, pede ao amigo uma versão do texto publicado, porque não mais o possui. Mas, está atento, pois informa que outros foram publicados com erros de revisão. Mas deposita grande confiança no amigo quando lhe manda versos para que os publique. E não é sem razão que em carta de setembro de $1927^{55}$, Durval de Moraes pergunta a Arthur de Salles:

Porque nunca mais me mandastes um verso? ${ }^{56}$

\section{$2.1 \mathrm{O}$ resultado da recensio}

O projeto Levantamento em Periódicos da Obra Dispersa de Arthur de Salles tem catalogado grande parte da obra dispersa, mas muito ainda precisa ser feito. Dos poemas contidos nas cartas a Durval de Moares, as sete cartas-poema jamais foram publicadas. Os demais poemas, mesmo antes de integrarem o livro Poesias, tiveram publicação neste ou naquele periódico. A té ao momento, a pesquisa já conseguiu recensear os seguintes textos:

\footnotetext{
${ }^{55}$ Não traz o dia do mês.

${ }^{56}$ Cf. doc. PR-EP/RE-OM-IN-043:0214-NX:01/DC.
} 
Título

D. Quixote

Poesias

- Cavalleiro das Horas Poesias

Mortas / Ballada

Praia em festa

Poesias

Purpuras

Poesias

O cão de bordo

Poemas do mar

Sub umbra

Sub umbra $\$ 7$

Os Mulungus
Coletânea

Publicação em Periódica
A Fita, Bahia, ano $1, \mathrm{n} .5,[\mathrm{p}$. 19], 16 abr. 1919

Bahia Iliustrada, Rio, ano 3.

n. 18, p. [17], mar. 1919

A Cegonha, Balia, ano $1,11$.

5. [p. 20], abr. 1918

Bahia Illustrada, Rio, ano 2,

n. 4, [p. 7], mar.1918

Nova Cruzada, Balia, ano 1, n. 8, p. 8, jan. 1903

Veneza Americana. Recife, [s.p.], set. 1946

A Luva, Bahia, ano 2, 11. 25. [p. 15], mar. 1926

$\mathrm{RCI}$

Bahia Illustrada, Rio, ano 2 , n. 4, [p. 7], mar. 1918

Desses textos, pelo menos três, poderiam ter sido publicados com a intervenção de Durval de Moraes:

O Cavalleiro das Horas Mortas / Ballada (jul. 1910)

Praia em festa (s.d.)

Sub umbra (16 de maio de 1924)

Por outro lado, quatro deles integram o livro Poesias ${ }^{58}$, um faz parte da coletânea que estava a preparar dos Poemas do mar ${ }^{59}$, e o último (com duas versões) faz parte da Obra dispersa, além do fato de uma das duas versões autógrafas ter sido enviada junto a uma carta com ordem para Durval de Moraes fazer o que quisesse. A crônica Os Mulungus, como se disse antes, tem como original o texto de uma carta, datada de 8 de dezembro de $1911^{60}$.

O dossiê Arthur de Salles mostra ainda outros poemas que poderiam ter seguido o mesmo caminho:

\footnotetext{
${ }^{57} \mathrm{Cf}$. Arthur de SALLES. Poesias; 1901-1915...

${ }^{58}$ Cf. Rosa Santos Carvalho BORGES, op. cit. Como jả se assinalou, Rosa Borges continua a trabalhar nos Poemas do mar em sua tese de Doutorado.

${ }^{59}$ Cf. doc. 062:0254.

${ }^{60}$ Cf. doc. 070: 0391.
} 
Título

Natal

Suicida
Coletânea

Poesias

Poesias
Publicação em Periódico

Bahia Illustrada, Rio, ano 3 , n.14, p.[381], jan. 1919

Bahia Illustrada, Rio, ano 2, n. 4, s.n.p., mar. 1918

Gazeta do Povo, Salvador, ano 6 , n. $1666,18.03 .1911$, p. 2

\section{CONSIDERAÇÕES FINAIS}

Do exposto, crê-se ter podido mostrar um pouco da trajetória entre a carta e a subseqüente impressào de algumas das obras de Arthur de Salles. Sobretudo quando se recordam as próprias palavras do poeta, ao remeter ao amigo os poemas Veneza e Sub umbra, anexos à carta de 16 de maio de $1924^{61}$ : "... Ahi vão estes versos que encontrei mais a mào, (...), Faze delles o que quiseres... ${ }^{62}$.

"Cf. doc. 070:0391.

${ }^{62}$ Cf. id., ibid. 